\title{
The Evolution of the Number of Abortions in the Omsk Region for 2005-2015
}

\section{Abstract}

The aim of the study was to analyze the dynamics of abortion in the Omsk region in recent years in comparison with the Russian Federation and the Siberian Federal district. Materials and methods: the study analyzed data of the official statistics of abortions for 2005-2015 has been applied the epidemiological method of research.

Keywords: Contraception; Reproductive health; Abortion

Received: Febraury 05, 2018; Accepted: Febraury 13, 2018; Published: February 20, 2018

\section{Relevance}

No doubt the fact that the need for artificial termination of pregnancy remains a persistent tendency of the present time. The society is not able to completely eliminate abortion as a means of birth control [1]. In modern Russia the problem of abortion remains highly relevant. Thus in 2015 it produced 848180 induced abortions, which corresponds to the population of a large city. While aborted pregnancies from 15 to 19 years had occasion, from 20 to 34 years-603342, 35 years and older-213480 case.

Despite the wide choice of contraceptives, the number of unwanted pregnancies at present is $41 \%$ [2] of all pregnancies and exceeds a similar indicator of the developed countries in 2 times, therefore, the prevention of unwanted pregnancy remains a major problem [3].

At present, the traditional value attitude to childbirth and motherhood is lost. A consequence of the loss of these values is the demographic crisis-the small families today life is becoming the norm: half of Russian families have only one child, the parents often do not to the birth of subsequent children, citing his lack of money, time and effort. As numerous socio-psychological research, the reluctance to have children is not due to material situation of the family, and moral and spiritual crisis. In society the transformation of traditional family values. The choice of young people is increasingly falling on the achievement of career growth, creating a family is postponed to the improvement of social and living conditions, and reproductive age extended from 20-25 to 30-35 years. In addition, today's youth is losing value against the marriage, preferring to engage in extramarital sexual relations to minors, without thinking about their consequences [4].

\section{Kravchenko EN, Morgunov RA* and Kryvchyk GV}

Department of Obstetrics and Gynecology, Ministry of Health of the Russian Federation, Omsk State Medical University, Russian

\section{*Corresponding author: Morgunov RA \\ ”roman15_02@mail.ru}

Department of Obstetrics and Gynecology, Ministry of Health of the Russian Federation, Omsk State Medical University, Russian.

Tel: 89045873512

Citation: Kravchenko EN, Morgunov RA, Kryvchyk GV (2018) The Evolution of the Number of Abortions in the Omsk Region for 2005-2015. J Contracept Stud Vol.3 No.1:4

Thanks to government measures (maternity capital, birth certificates, social support of large families, etc.), the birth rate in our country has managed to increase, but population growth in large cities and Metropolitan areas to a lesser degree is due not to a newborn of their inhabitants, and related to the migration of the adult population. As a result, the number of the indigenous population decreases. Therefore the problem of increase of birth rate acute in every major city. One of the solutions is the formation of urban women of installations on the birth of children and, therefore, the rejection of such measures as the termination of pregnancy [5].

One of the main directions of improving the demographic situation in the country is the promotion of reproductive health and the preservation of the childbearing function of women, which is directly related to a decrease in the number of abortions, prevention of which is directly connected with the use of modern contraceptive methods to prevent unwanted pregnancy $[6,7]$.

In the Russian Federation, hormonal contraception is not the primary method of birth control [3]. At the same time, a survey of women 18-45 years have shown that they are actively using contraception (all methods $-85 \%$ state $-68 \%$ ). This coincides with the data World abortion policies (80/60\%) and higher than the global average (63/57\%) and comparable with developed countries (72/62\%), the maximum of which is marked in Norway 
$(88 / 82 \%)[3,8]$.

The risk of side effects and adverse effects of hormonal contraception does not exclude the necessity of controlling fertility in patients suffering from diseases and conditions that pose a threat to life and health upon the occurrence of unplanned pregnancy, including adolescent girls $[9,10]$.

The purpose of the study: The aim of the study was to analyze the dynamics of abortion in the Omsk region in recent years in comparison with the Russian Federation and the Siberian Federal district.

\section{Materials and Methods}

The study analyzed data of the official statistics of abortions for 2005-2015 has Been applied the epidemiological method of research. The results showed that the frequency of abortions depending on the age of women in the Russian Federation as a whole has a positive trend (Figure 1). The highest percentage reduction in the number of abortions since 2005 and 2015 amounted to $81,2 \%$ in the $15-19$ age group.

So, if in 2005 the number of interrupted pregnancies in the age group 15-19 years was 165 674, 20-34 years - 1200371 and older than 35 years - 308 626, in 2015 the situation has changed for the better: in the 15-19 age group produced 31078 abortion, 20-34 years old - 603 342, over 35213480 .

When analyzing the frequency of abortions depending on the age of the women in the Siberian Federal district, asking that in the 1519 age group was $30999,20-34$ years - 209885 and over the age of $35-47003$, in 2015 , there are some positive developments: at the age of 15-19 years completed 6440 abortion, 20-34 years old - 110 599, over the age of 35-36 442 (Figure 2). The highest percentage reduction in the number of abortions in the Siberian Federal district and in the whole of Russia, 2005 to 2015 is observed in the age group 15-19 years was $79.2 \%$.

When assessing the frequency of abortions depending on the age of women in the Omsk region, of course, is clearly traced their decline, at the same time, the pace of decline in the frequency of abortions is quite low and the greatest number of abortions occur in the age of 20-34 years (Figure 3). The highest percentage reduction in the number of abortions in the Omsk region, as well as in the whole of Russia, Siberian Federal district from 2005 to 2015 is observed in the $15-19$ age group and was equal to $88.2 \%$.

We analyzed the causes of low rates reduce the occurrence of unintended pregnancy and abortion in the Omsk region. These include the misconceptions about fertility and improper use of contraceptives in young women; in society it is not enough open discussion of adolescent sexuality; also the population as a whole is still insufficiently informed about the possibilities and planning of pregnancy [11]. The same reason a large number of abortion describe by other authors. In countries where openly discussed the problems of teenage sexuality and sex education and contraception where public, the least rate of abortions [1].

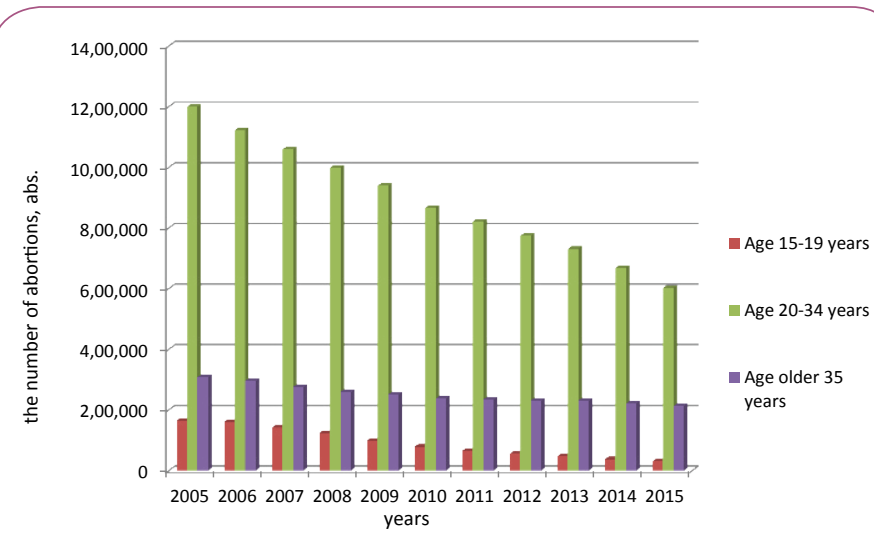

Figure 1 Frequency of abortions depending on the age of women in the Russian Federation.

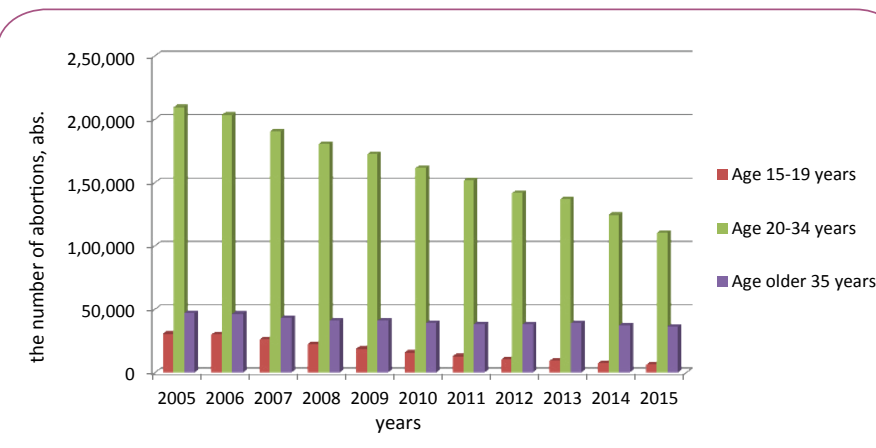

Figure 2 Frequency of abortions depending on the age of the women in the Siberian Federal district.

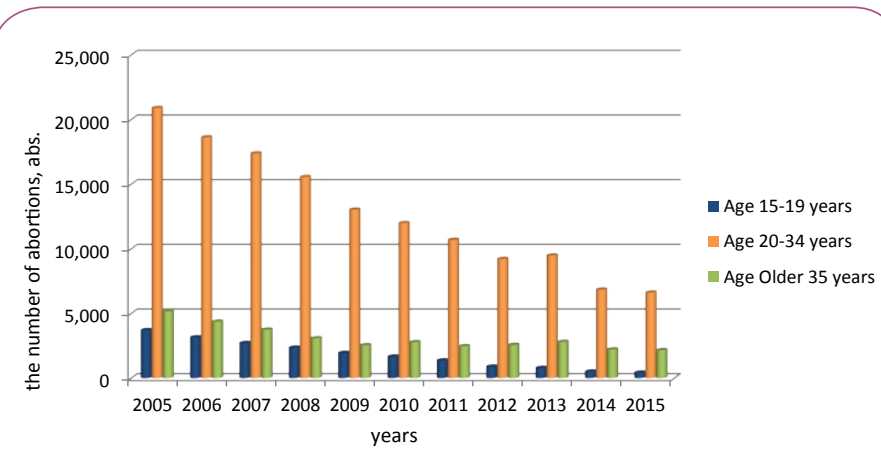

Figure 3 Frequency of abortions depending on the age of women in the Omsk region.

\section{Conclusion}

The study showed that the frequency of abortions has been steadily declining, which is a positive thing, but the rate of decline in frequency of abortions remains insufficient, because the figures are great. Most abortions occur in the age of 20-34 years, the most favorable period for pregnancy, which is a very negative factor for demography of the Omsk region.

To further enhance the effectiveness of the anti-abortion team work is required, aimed at strengthening the educational work among young people, in particular among school children (promotion of family values, responsible attitude to parenthood); 
the inclusion in the training of students of higher and secondary medical educational institutions of techniques for the prevention of abortion [12]; advice and selection of optimal methods of contraception; monitoring the reproductive behavior of women following abortion and childbirth, especially when the occurrence of unintended pregnancy.

\section{References}

1 Mazza D (2017) Handbook of gynaecology D. Mazza; translated from English. Sukhikh GT, Apoligies IAM editors. Practical Medicine 568.

2 Safe Abortion (2012) Technical and Policy Guidance for Health Systems [Electronic resource]. (2 edn.), Geneva: WHO 123.

3 Manual of outpatient care in obstetrics and gynecology. Serova VN editor. (3rd edn.), Rev. and DOP. Moscow: GEOTAR-Media, 20161136.

4 Kononova N (2017) The problem is the attitude towards abortion among the youth. Materials of conference "Topical issues of social work with different categories of the population"-Kirov 197-206.

5 Kurakov DA, Bondarenko AS, Shestakov AA (2014) Social profile, the attitude towards abortion residents of large industrial city. Urban Sociology 37-44.

6 Adamyan LV, Sibirskaya EV, Bogdanova EA, Koltunov IE, Small TA (2016) Reproductive health of girls and young women of Moscow. Proposals for preservation of reproductive potential. Reproductive Health of Children and Adolescents 2: 13-14.
7 Sinchikhin SP, Mamiev OB (2013) Socio-medical aspects of the interruption of unwanted pregnancies. Effective pharmacology 51: 30-35.

8 World abortion policies (2013) United Nations, Department of Economic and Social Affairs, Population Division.

9 Kravchenko EN, Mordyk AV, Puzyreva LV, Valeeva GA (2016) Hormonal contraception in patients of risk groups (literature Review). Problems of Reproduction 1: 60-66.

10 Uvarova EV, Spiridonova N. Kazakov VA (2016) The Relationship between knowledge about contraception and its use among adolescent girls of secondary special institutions. Samara. Reproductive Health of Children and Adolescents 3: 85-95.

11 Morgunov RA, Kravchenko EN (2017) Features contraception in Russia in the Omsk region. Doctor-graduate student 5: 84-91.

12 Filippov OS, Tokova ZZ, Gata AS, Kuzemyn AA, Gudimova VV (2016) Abortion: statistics features in Federal districts of Russia. Gynecology 01: 92-96. 